\title{
TECNOLOGIA A SERVIÇO DO ACESSO À JUSTIÇA: MEIOS ADEQUADOS DE RESOLUÇÃO DE CONFLITOS NA SOCIEDADE MODERNA ${ }^{1}$
}

TECHNOLOGY IN THE SERVICE OF ACCESS TO JUSTICE: ADEQUATE MEANS OF RESOLUTION OF CONFLICTS IN THE MODERN SOCIETY

Rozane da Rosa Cachapuz Doutora em Direito Internacional, com ênfase em Direito de Família, pela Pontifícia Universidade Católica de São Paulo (PUCSP), mestrado em Direito Negocial, nas áreas de Civil e Processo Civil, pela Universidade Estadual de Londrina (UEL). Graduação em Direito pela Universidade da Região da Campanha (URCAMP). Professora da Universidade Estadual de Londrina (UEL). Coordenadora dos cursos de Pósgraduação em Direito Empresarial, Direito de Família à Luz da Responsabilidade Civil, da Universidade Estadual de Londrina (UEL).

Londrina/PR.

E-mail: rozane_cachapuz@hotmail.com

Alexia Domene Eugenio Mestranda em Direito Negocial pela Universidade Estadual de Londrina (UEL). Especialista em Direito Constitucional pela Faculdade Internacional Signorelli (FISIG). Graduação em Direito pelo Centro Universitário Antônio Eufrásio de Toledo. Mediadora e Conciliadora certificada pelo Conselho Nacional de Justiça. Advogada. Presidente Prudente/SP. E-mail: alexiadomene@gmail.com

RESUMO: A sociedade de informação possui relação intrínseca com a tecnologia, que deve ser assimilada não apenas pelos particulares, mas também pelo Estado em suas esferas de

\footnotetext{
${ }^{1}$ Artigo recebido em 03/03/2020 e aprovado em 09/06/2021.
} 
Poder, entre elas, o Poder Judiciário. Propõe-se a análise do uso da tecnologia para consecução da sua prestação principal - a jurisdicional - em prol do efetivo acesso à justiça, através da implantação de meios digitais de solução de conflitos, denominados ODR Online Dispute Resolution. Emprega-se o método dedutivo, ao abordar a sociedade de informação, os principais aspectos do acesso à justiça e dos meios de solução de conflitos para, enfim, aliá-los ao emprego da tecnologia.

PALAVRAS-CHAVE: Acesso à justiça. Autocomposição. Online Dispute Resolution. Sociedade da informação. Solução de Conflitos.

ABSTRACT: The information society has an intrinsic relationship with technology, which must be assimilated not only by individuals, but also by the State in its spheres of power, including the Judiciary. The purpose is to analyze the use of technology to achieve its main provision - the jurisdictional one - in favor of effective access to justice, through the implementation of digital means of conflict resolution, called ODR - Online Dispute Resolution. The deductive method is used to addess the information society, the main aspects of access to justice and the means of conflict resolution to, in short, combine them with the use of technology.

KEYWORDS: Access to justice. Autocomposition. Online Dispute Resolution. Information society. Conflict Resolution.

\section{INTRODUÇÃO}

Em face da fluidez da realidade, observam-se cada vez mais rápidas mudanças sociais, econômicas, culturais, e especialmente, tecnológicas. Tal desenvolvimento tecnológico das últimas décadas promove constante revolução na forma como as pessoas vivem, contudo, além disso, surge para o próprio Estado um dever de adaptar-se e utilizar em seu benefício as inovações que fazem parte do cotidiano dos indivíduos. Desse modo, é de grande importância observar como a tecnologia pode contribuir para a concretização do acesso à justiça, escopo primordial do Poder Judiciário. 
Busca-se, através de um estudo sobre o acesso à justiça e suas acepções, aliada à análise de dados sobre a situação concreta da inclusão digital e os obstáculos existentes, verificar de que modo a tecnologia relaciona-se com a prestação jurisdicional e, especialmente, demonstrar a eficiência e necessidade de métodos de solução de conflitos pela via digital.

Entre os aspectos abordados no trabalho, tem-se a princípio, a evolução dos meios "alternativos" de solução do conflito, a "crise" do Poder Judiciário, em seguida a informatização e o processo eletrônico, para, enfim, analisar-se a execução de uma política judiciária que inclui a resolução digital de conflito através de plataformas específicas - as ODR (Online Dispute Resolution).

Quanto à metodologia, emprega-se o método dedutivo, abordando os principais aspectos do acesso à justiça, dos meios de solução de conflitos e da tecnologia em prol de tais conceitos. A pesquisa tem como base uma bibliografia atualizada com as mais recentes inovações legislativas e resoluções sobre o tema, bem como dados estatísticos recentes que refletem a atualidade, para se atinjam os objetivos propostos, ou seja, que a tecnologia pode ser uma aliada do Poder Judiciário para cumprir sua principal prestação, e, por conseguinte, efetivar o acesso à justiça por diversos meios.

\section{ACESSO À JUSTIÇA E OS NOVOS PARADIGMAS NA SOCIEDADE DE INFORMAÇÃO}

Uma das características marcantes do momento em que a sociedade se encontra é a instabilidade e a fluidez da vida em si. De acordo com a teoria de Zygmunt Bauman, vivese uma "modernidade líquida", na qual tudo é temporário, volátil. Pode-se observar que um emprego na mesma empresa poderia ser considerado um sonho há algumas décadas, e, atualmente, trabalhar a vida inteira no mesmo lugar é algo indesejado por muitos. É atrativa a mudança de emprego, de residência, de país, de hobby, além de ser criada uma atmosfera de consumo exagerado, voltado a vender não só produtos e serviços, mas também estilos de vida. Há uma "liquefação dos padrões", do tempo, do espaço, do trabalho e da comunidade 2 .

\footnotetext{
${ }^{2}$ BAUMAN, Zygmunt. Modernidade líquida. Tradução Plínio Dentzien. Rio de Janeiro: Jorge Zahar Ed., 2001. p. 14.
} 
Não apenas há uma instabilidade no modo de vida, mas também das instituições sociais, que se adaptam constantemente à dinâmica social em que estão inseridas - trata-se de uma necessidade. Um dos elementos que contribuíram fundamentalmente para a aceleração do processo de "liquidez social" foi a universalização do acesso à internet - que, num breve histórico, foi inicialmente foi criada com fins militares, sendo posteriormente usada para fins científicos e de pesquisa nas universidades. Anos depois, permitiu-se sua exploração pela iniciativa privada, expandindo o acesso antes restrito.

No Brasil, especificamente, em 1989 foi desenvolvido um sistema (Rede Nacional de Pesquisa) para o uso científico do Ministério da Ciência e Tecnologia e, em 1995, provedores de acesso discado da iniciativa privada foram autorizados a serem explorados economicamente ${ }^{3}$.

A expansão da internet é significativa para caracterizar a disseminação irrestrita de informação e dos mais diversos conteúdos, globalizando a comunicação, a divulgação de notícias, o comércio eletrônico - a vida está na rede, em um espaço de fluxos totalmente novo ${ }^{4}$. Por tais motivos, a doutrina consolida a nomenclatura da sociedade atual como a "sociedade de informação".

\subsection{Apontamentos sobre a sociedade de informação}

O surgimento da ideia da sociedade da informação se deu em razão da ampla possibilidade de trocas de conteúdo através da rede mundial de computadores, em que qualquer pessoa que possua acesso à rede pode informar, se informar e ser informado. A informação - seja em formato de palavra, som, vídeo, imagem etc. -, portanto, é elemento chave da relação do mundo com a tecnologia.

\footnotetext{
${ }^{3}$ EUGENIO, Alexia Domene; LIGERO, Gilberto Notário. A internet como veículo libertário: a incorporação da rede na vida social. In: Anais do III Simpósio Internacional de Análise Crítica do Direito. Jacarezinho, PR: Universidade Estadual do Norte do Paraná, 2013. p. 2176-2190. Disponível em: http://siacrid.com.br/repositorio/2013/anais-do-iii-simposio-de-analise-critica-do-direito.pdf Acesso em: 10 dez. 2019. p. 2179-2180.

${ }^{4}$ CASTELLS, Manuel. A sociedade em rede. A era da informação: economia, sociedade e cultura. v. 1. Tradução Roneide Venancio Majer. 6. ed. 2002.
} 
Segundo André Lemos e Pierre Lévy ${ }^{5}$, a cibercultura promoveu o surgimento de um paradigma informacional, aquele "que traduz o mundo em dados binários", em informação. Destarte, com essa tradução informacional do mundo, tudo pode ser processado e distribuído em tempo real para todo e qualquer lugar do planeta. A informação disseminada não encontra limites geográficos ou transfronteiriços ${ }^{6}$ :

A informação disponível é incontrolável à medida que se espalha para diversos sites, atingindo pessoas com diferentes culturas, diferentes maneiras de interpretar o conteúdo ali exposto e contribuindo para a diversificação dos pontos de vista que podem ser encontrados pela rede. Com isso, a ideia de território coincide com a de informação ou expressão. A informação na rede é, pois a base da ideia de território, de ciberespaço.

É indiscutível a abrangência que as ferramentas tecnológicas podem alcançar, mas não significa que seja fácil o acesso, ou que seja simples o seu uso. Pelo contrário, muitas vezes é cara a obtenção de um serviço de provedor de internet, bem como nem sempre é trivial o funcionamento de um aparelho eletrônico, conforme dados específicos mostram a respeito do tema da inclusão e da exclusão digital.

Na pesquisa “TIC Domicílios” (uso de Tecnologias de Informação e Comunicação nos domicílios brasileiros) referente ao ano de 2017, realizada pelo Cetic.br ${ }^{7}$, um departamento do quadro do Comitê Gestor da Internet no Brasil, pode-se observar uma melhora no quadro, mas ainda havendo disparidades quando consideradas a área rural, a instrução do indivíduo e a renda mensal.

Muito embora o percentual de domicílios com acesso à internet registrado tenha sido de $61 \%$ em 2017, representando um aumento de 7\% com relação ao ano de 2016, “desigualdades regionais e socioeconômicas persistem em níveis semelhantes, com maiores percentuais de domicílios conectados em áreas urbanas (65\%) e nas classes A (99\%) e B

\footnotetext{
${ }^{5}$ LEMOS, André; LÉVY, Pierre. O futuro da internet: em direção a uma ciberdemocracia. São Paulo: Paulus, 2010. p. 22.

${ }^{6}$ EUGENIO, Alexia Domene; LIGERO, Gilberto Notário. A internet como veículo libertário: a incorporação da rede na vida social. In: Anais do III Simpósio Internacional de Análise Crítica do Direito. Jacarezinho, PR: Universidade Estadual do Norte do Paraná, 2013. p. 2176-2190. Disponível em: http://siacrid.com.br/repositorio/2013/anais-do-iii-simposio-de-analise-critica-do-direito.pdf Acesso em: 10 dez. 2019. p. 2185-2186.

${ }^{7}$ É possível encontrar dados relevantes que confirmam as conclusões do relatório "TIC Domicílios - Cetic.br" também na estatística do Instituto Brasileiro de Geografia e Estatística (IBGE). Trata-se da "Pesquisa Nacional por Amostra de Domicílios Contínua - PNAD Contínua" sobre Acesso à Internet e Celular, de 2017, disponível no endereço https://biblioteca.ibge.gov.br/visualizacao/livros/liv101631_informativo.pdf
} 
Rio de Janeiro. Ano 15. Volume 22. Número 3. Setembro a Dezembro de 2021

Periódico Quadrimestral da Pós-Graduação Stricto Sensu em Direito Processual da UERJ

Patrono: José Carlos Barbosa Moreira (in mem.). ISSN 1982-7636. pp. 981-1005 www.redp.uerj.br

(93\%), frente a percentuais ainda reduzidos entre domicílios de áreas rurais (34\%) e classes DE $(30 \%) " \%$.

Segundo as informações coletadas, entre os domicílios sem conexão à Internet, que são os $39 \%$ restante dos domicílios, o motivo mais citado é o alto custo do serviço (27\% dos entrevistados sem acesso), seguido pela falta de interesse e por não saberem utilizar a internet $(16 \% \text { em ambos })^{9}$.

Outro dado a ser trazido da pesquisa é com relação ao "Governo Eletrônico", que constitui uma política governamental de realização de serviços públicos pela internet. Tais serviços podem ser coleta e organização de informações, agendamento e antecipação de etapas de serviços que otimizem a prestação presencial, emissão de certidões, entre outras formas de serviços. O relatório da pesquisa demonstrou que as atividades mais realizadas incluindo busca de informação e realização parcial do serviço via internet - dizem respeito a direitos do trabalhador ou previdência social (28\%), educação pública (28\%) e documentos pessoais $(27 \%)^{10}$.

Observa-se que o uso da tecnologia em serviços públicos vem sendo ampliado, mas ainda é limitado, não alcançando amplamente todos os serviços. Sobre tal limitação, Fabiana Marion Spengler e Humberto Dalla Bernardina de Pinho ${ }^{11}$ comentam sobre a promoção tardia da inclusão digital no Brasil pelo Estado:

Nesse contexto, é importante verificar que a inclusão digital no Brasil é relativamente recente, pois o Programa Nacional de Apoio à Inclusão Digital nas Comunidades só foi instituído pelo Decreto nº 6.991/2009, dentro da política de inclusão digital do Governo Federal. O objetivo dessa inclusão foi desenvolver ações que implantassem e a mantivessem

\footnotetext{
${ }^{8}$ COMITÊ GESTOR DA INTERNET (CGI). Pesquisa sobre o uso das tecnologias de informação e comunicação nos domicílios brasileiros: TIC domicílios (2017). Núcleo de Informação e Coordenação do Ponto BR - São Paulo: Comitê Gestor da Internet no Brasil, 2018. Disponível em: https://www.cetic.br/pesquisa/domicilios/publicacoes Acesso em: 02 dez. 2019. p. 112.

${ }^{9}$ COMITÊ GESTOR DA INTERNET (CGI). Pesquisa sobre o uso das tecnologias de informação e comunicação nos domicílios brasileiros: TIC domicílios (2017). Núcleo de Informação e Coordenação do Ponto BR - São Paulo: Comitê Gestor da Internet no Brasil, 2018. Disponível em: https://www.cetic.br/pesquisa/domicilios/publicacoes Acesso em: 02 dez. 2019. p. 116.

${ }^{10}$ COMITÊ GESTOR DA INTERNET (CGI). Pesquisa sobre o uso das tecnologias de informação e comunicação nos domicílios brasileiros: TIC domicílios (2017). Núcleo de Informação e Coordenação do Ponto BR - São Paulo: Comitê Gestor da Internet no Brasil, 2018. Disponível em: https://www.cetic.br/pesquisa/domicilios/publicacoes Acesso em: 02 dez. 2019. p. 132.

${ }^{11}$ SPENGLER, Fabiana Marion; PINHO, Humberto Dalla Bernardina de. A mediação digital de conflitos como política judiciária de acesso à justiça no Brasil. Revista da Faculdade de Direito UFMG. Belo Horizonte, n. 72, pp. 219-257, jan./jun. 2018.2 Disponível em: https://www.direito.ufmg.br/revista/index.php/revista/article/viewFile/1923/1817 Acesso em: 29 nov. 2019. p. 231.
} 
telecentros públicos e comunitários no território nacional. No ano de 2010, criou-se o Programa Nacional de Banda Larga (PNBL), pelo Decreto $\mathrm{n}^{\circ}$ 7.175/ 2010, que possui finalidade de fomentar e difundir o uso e o fornecimento de bens e serviços de tecnologias de informação e comunicação.

Em que pese ainda estar em evolução a disseminação do acesso às tecnologias, os serviços públicos já possuem difusão em alguns setores. Dentre as existentes formas de prestação de serviços online, recebem destaque, conforme a doutrina, a declaração de Imposto de Renda online, a emissão de certidões e outros documentos relevantes, cadastramento em bancos de dados públicos, acesso à informação pública e transparência, bem como o acompanhamento de processos judiciais ${ }^{12}$.

Justamente, chega-se ao ponto de contato entre a tecnologia e o Poder Judiciário, uma das faces da soberania estatal que, no desempenho de suas funções, não pode deixar de se adaptar à nova realidade informacional e tecnológica - uma irreversível realidade.

\subsection{O Uso da Tecnologia em Prol do Acesso à Justiça: Primeiras Linhas}

Quando o constituinte assegurou, no art. $5^{\circ}$, inciso XXXV, que "a lei não excluirá da apreciação do Poder Judiciário lesão ou ameaça a direito", propôs-se uma reflexão muito mais ampla que a possibilidade de ajuizamento de uma ação judicial, não se trata apenas da inafastabilidade da jurisdição no sentido formal.

$\mathrm{O}$ acesso à justiça, de acordo com a lição de Mauro Cappelletti e Bryan Garth ${ }^{13}$, "serve para determinar duas finalidades básicas do sistema jurídico - o sistema pelo qual as pessoas podem reivindicar seus direitos e/ou resolver seus litígios", isto é, possui uma dupla acepção, dois sentidos: "Primeiro, o sistema deve ser igualmente acessível a todos; segundo, ele deve produzir resultado que sejam individual e socialmente justos."

Não se pode deixar um ou outro sentido de lado, pois ambos se completam e proporcionam efetivo acesso à justiça, porém, os autores destacam que a segunda finalidade pressupõe a primeira ${ }^{14}$, de modo que a obtenção de resultados justos depende da existência de mecanismos eficazes a essa finalidade. Atualmente, é preciso adaptar a doutrina às

\footnotetext{
${ }^{12}$ LEMOS, André; LÉVY, Pierre. O futuro da internet: em direção a uma ciberdemocracia. São Paulo: Paulus, 2010. p. 24.

${ }^{13}$ CAPPELLETTI, Mauro; GARTH, Bryant. Acesso à justiça. 1 ed. Porto Alegre: Sergio Fabris, 1988. p. 8

${ }^{14}$ CAPPELLETTI, Mauro; GARTH, Bryant. Acesso à justiça. 1 ed. Porto Alegre: Sergio Fabris, 1988. p. 8
} 
possibilidades existentes - e tal ideia será melhor aprofundada em seguida -, entretanto, já se adianta que, mesmo sem acessar o Poder Judiciário propriamente dito, é possível observar a concretização do acesso à justiça, por exemplo, através da conciliação pré-processual.

No que tange à tecnologia contribuindo para a concretização do acesso à justiça, a informatização administrativa e processual e a eficiência do processo eletrônico, regulamentado de forma específica pela Lei $\mathrm{n}^{\circ}$ 11.419/2006, são aliados cruciais, de acordo com Fabiana Marion Spengler e Humberto Dalla Bernardina de Pinho ${ }^{15}$ :

É por meio desses equipamentos (computador, telefone celular, tablet, etc), que interligam as redes digitais, que o cenário do acesso à justiça se transforma. Essa transformação diz respeito ao modo de ingressar, de se comunicar, de se manifestar e, também, ao modo de sentenciar. Essas alterações de acesso - do físico para o eletrônico - podem ser sentidas no cenário jurídico brasileiro especialmente após a introdução do processo eletrônico.

Em seu relatório "Justiça em Números", o Conselho Nacional de Justiça coletou dados sobre a informatização de processos. Segundo o relatório, "Durante o ano de 2018, apenas $16,2 \%$ do total de processos novos ingressaram fisicamente. Em apenas um ano, entraram 20,6 milhões de casos novos eletrônicos."16. Realizando um comparativo com a primeira vez que se fez a pesquisa sobre este aspecto, em 2009, os processos digitais eram 11,2\% do total dos processos. Em 2019, ou seja, 10 anos depois, a adesão ao processo digital chegou a 83,8\%, e, ainda sobre essa evolução, segundo o relatório, "Nos 10 anos cobertos pela série histórica, foram protocolados, no Poder Judiciário, 108,3 milhões de casos novos em formato eletrônico." 17

Em que pese a existência de tais índices, e de uma economia de recursos, insumos e de tempo na administração do processo digital, ainda há uma intensa discussão sobre a

\footnotetext{
${ }^{15}$ SPENGLER, Fabiana Marion; PINHO, Humberto Dalla Bernardina de. A mediação digital de conflitos como política judiciária de acesso à justiça no Brasil. Revista da Faculdade de Direito UFMG. Belo Horizonte, n. 72, pp. 219-257, jan./jun. 2018.20 Disponível em: https://www.direito.ufmg.br/revista/index.php/revista/article/viewFile/1923/1817 Acesso em: 29 nov. 2019. p. 230.

${ }^{16}$ CONSELHO NACIONAL DE JUSTIÇA (CNJ). Justiça em Números 2019: (ano base 2018). Brasília: Conselho Nacional de Justiça, 2019.2 Disponível em: $\langle$ https://www.cnj.jus.br/files/conteudo/arquivo/2019/08/4668014df24cf825e7187383564e71a3.pdf > Acesso em: 30 nov. 2019. p. 95.

${ }^{17}$ CONSELHO NACIONAL DE JUSTIÇA (CNJ). Justiça em Números 2019: (ano base 2018). Brasília: Conselho Nacional de Justiça, 2019.2 Disponível em: $\langle$ https://www.cnj.jus.br/files/conteudo/arquivo/2019/08/4668014df24cf825e7187383564e71a3.pdf > Acesso em: 30 nov. 2019. p. 95.
} 
existência de uma "crise" no Poder Judiciário, que leva a um reconhecimento de meios "alternativos" como iguais.

\section{RESOLUÇÃO DE CONFLITOS NA SOCIEDADE MODERNA E O USO DA TECNOLOGIA}

A forma como os conflitos são tratados é determinante para a satisfação das partes e para a prevenção de futuros conflitos derivados. O Estado, ao avocar para si o monopólio da jurisdição, adotou o papel de aplicador das normas jurídicas, através de um rito com prazos e formas preestabelecidos, que, apesar das boas intenções, não é capaz de acompanhar a dinâmica social e o aumento da complexidade dos litígios. É possível vislumbrar o longo caminho que foi percorrido para desenvolver, por exemplo, regras de processo coletivo e de conflitos transindividuais, formas de atender às demandas da população financeiramente carente, de tentar lidar com a instalação de unidades judiciais, equipamentos e servidores, além da própria questão numérica dos processos - gerada pelo próprio Estado ao monopolizar a solução de conflitos.

\subsection{A “Crise" da Prestação Jurisdicional: Necessidade de Reconhecimento de Outros}

\section{Meios}

A "cultura da sentença" foi uma expressão cunhada por Kazuo Watanabe ${ }^{18}$, ao propor uma crítica à formação de magistrados e outros profissionais de Direito, que não se preocupavam com a solução não-contenciosa e menosprezavam meios alternativos de solução de conflito, resultando em profissionais que não sabem lidar com os conflitos de maneiras diversas da tradicional.

Este comportamento e formação contribuem, como consequência lógica, à denominada "crise" do Poder Judiciário, com prejuízos à duração razoável do processo, à efetividade do cumprimento de decisões, ao acesso à justiça e segurança jurídica de socorrerse ao Judiciário. Para melhor compreensão, Charlise Paula Colet Gimenez e Fabiana Marion

18 WATANABE, Kazuo. Cultura da sentença e cultura da pacificação. In: YARSHELL, Flávio Luiz. MORAES, Maurício Zanoide de. (Org.) Estudos em homenagem à professora Ada Pellegrini Grinover. São Paulo: Editora DPJ, 2005. p. 689. 
Spengler ${ }^{19}$ trazem duas causas fundamentais para a situação que se encontra o Poder Judiciário:

[...] a crise do Judiciário perpassa por dois pontos: a) crise de identidade, aqui compreendida enquanto embaçamento do papel do Poder Judiciário como mediador central dos conflitos, perdendo espaço para outros centros de poder, talvez mais aptos a lidar com a complexidade dos conflitos; b) e crise de eficiência, vista a partir da impossibilidade de responder de modo eficiente à complexidade social e litigiosa com a qual se depara.

As soluções, nesse sentido, não se podem ser destinadas a uma mera diminuição da demanda numérica de processos sem se atentar aos demais aspectos particulares dos $\operatorname{conflitos}^{20}$. É uma lógica reducionista que trata as consequências do problema e não suas causas, ou seja, uma prática incapaz de promover mudanças reais na forma como se lida com os conflitos.

Por certo, a busca por remédios que sanassem as mazelas da prestação jurisdicional promoveu uma busca por mudanças, e, num movimento a partir da década de 1970, as formas "alternativas" de solução de conflito ${ }^{21}$ foram impulsionadas como uma das possíveis opções à disposição das partes. Na obra de Mauro Cappelletti e Bryant Garth ${ }^{22}$, foram trazidas algumas medidas aptas a promover um efetivo acesso à justiça, divididas em três "ondas".

De forma sucinta, enquanto a primeira onda buscava melhor a tutela dos interesses dos economicamente hipossuficientes, com soluções como a assistência jurídica gratuita e instalação de juizados especiais, bem como melhoria em instrumentos de cidadania; a segunda onda tratava do processo de proteção de direitos metaindividuais, coletivos, ampliando o acesso à justiça à coletividade; a terceira onda de mudanças possui como foco melhor a efetividade da tutela, o que inclui a promoção dos meios "alternativos" de solução de conflito (“ADR - Alternative Dispute Resolution”).

Acerca da questão terminológica, a expressão "meios alternativos de solução de conflito" vem sendo há muito tempo discutida como inapropriada, pois implicaria numa

\footnotetext{
${ }^{19}$ GIMENEZ, Charlise Paula Colet. SPENGLER, Fabiana Marion. O mediador na resolução 125/2010 do CNJ: um estudo a partir do Tribunal Múltiplas Portas. 1. ed. Águas de São Pedro: Livronovo, 2016. p. 198.

${ }^{20}$ MANCUSO, Rodolfo de Camargo. Acesso à justiça: condicionantes legítimas e ilegítimas. Salvador: JusPodivm, 2018. p. 44.

${ }^{21}$ É tratado como berço do seu reconhecimento os Estados Unidos da América, especialmente a Frank Sander, professor emérito da Faculdade de Direito de Harvard, que cunhou a expressão "Tribunal Multiportas", em 1976, durante a Pound Conference, uma conferência ocorrida naquele ano em Minnesota, na qual foi palestrante convidado pelo próprio presidente da Suprema Corte dos Estados Unidos à época, Warren Burger (ALMEIDA, R., ALMEIDA, T., CRESPO, 2012, p. 31-32).

${ }^{22}$ CAPPELLETTI, Mauro; GARTH, Bryant. Acesso à justiça. 1 ed. Porto Alegre: Sergio Fabris, 1988. p. 72.
} 
subsidiariedade. Leonardo Carneiro da Cunha ${ }^{23}$ faz essa ressalva, ao defender que a ideia de uma justiça multiportas não trata de meios alternativos, mas sim adequados. Segundo ele, em razão de suas peculiaridades, cada conflito possui uma forma mais adequada para obter a melhor solução. A partir dessa perspectiva, haverá casos em que o próprio meio alternativo é a justiça estatal, transformada em uma segunda opção.

Dessa forma, na doutrina, a expressão "meios adequados de solução de conflito" é defendida por Leonardo Carneiro da Cunha, enquanto a expressão "meios complementares de solução de conflito" ${ }^{24}$, é empregada como mais apropriada por Charlise Paula Colet Gimenez e Fabiana Marion Spengler ${ }^{25}$, em que pese muitos ainda utilizem a denominação de "meios alternativos", mas sem um cunho pejorativo, apenas por tratar-se da forma como tradicionalmente foram chamados.

Apesar de o presente trabalho empregar o termo "adequados", considera-se que, seja como for a nomenclatura adotada, tais mecanismos, sem dúvida, correspondem a uma renovação necessária ao Poder Judiciário, em uma proposta de trazer a melhor solução para cada situação, sem que o Estado precise sempre se impor sobre as partes. Humberto Theodoro Júnior ${ }^{26}$ explica:

Fala-se, nesse sentido, na criação de novas vertentes para certos tipos de prestação jurisdicional, que enriqueceriam o processo com instrumentos capacitados a realizar a justiça que Cappelletti chama de coexistencial.

Em lugar de contar apenas com a força da autoridade legal do juiz, as partes poderiam, muitas vezes, obter melhores resultados na solução de seus conflitos, recorrendo à experiência e à técnica de pessoas capacitadas a promover a mediação e a conciliação, e chegando, assim, a resultados práticos mais satisfatórios do que os decretados pela justiça tradicional.

Portanto, "se o que importa é pacificar, torna-se irrelevante que a pacificação venha por obra do Estado ou por outros meios, desde que eficientes."27

\footnotetext{
${ }^{23}$ CUNHA, Leonardo Carneiro. Art. $1^{\circ}$ da Lei 13.140/2015. p. 1-7. In: CABRAL, Trícia Navarro Xavier. CURY, César Felipe. (Orgs.). Lei de mediação comentada artigo por artigo: dedicado à memória da Prof ${ }^{a}$. Ada Pellegrini Grinover. 1. ed. Indaiatuba, SP: Editora Foco, 2018. p. 1-2.

${ }^{24}$ CUNHA, Leonardo Carneiro. Art. $1^{\circ}$ da Lei 13.140/2015. p. 1-7. In: CABRAL, Trícia Navarro Xavier. CURY, César Felipe. (Orgs.). Lei de mediação comentada artigo por artigo: dedicado à memória da Prof . Ada Pellegrini Grinover. 1. ed. Indaiatuba, SP: Editora Foco, 2018. p. 2.

${ }^{25}$ GIMENEZ, Charlise Paula Colet. SPENGLER, Fabiana Marion. O mediador na resolução 125/2010 do CNJ: um estudo a partir do Tribunal Múltiplas Portas. 1. ed. Águas de São Pedro: Livronovo, 2016. p. 79.

26 THEODORO JÚNIOR, Humberto. Curso de direito processual civil - teoria geral do direito processual civil, processo de conhecimento e procedimento comum. vol. 1. 56. ed. Rio de Janeiro: Forense, 2015. p. 43.

${ }^{27}$ CINTRA, Antonio Carlos Araújo; GRINOVER. Ada Pellegrini; DINAMARCO, Cândido Rangel. Teoria geral do processo. 26. ed. São Paulo: Malheiros, 2010. p. 31.
} 
Mas, tendo em vista a realização do acesso à justiça, quais os meios adequados e eficientes que podem ser empregados?

O Código de Processo Civil de 2015, em seu art. $3^{\circ}$, traz uma ideia inicial, dispondo ${ }^{28}$ :

Art. $3^{\circ}$. Não se excluirá da apreciação jurisdicional ameaça ou lesão a direito.

$\S 1^{\circ}$. É permitida a arbitragem, na forma da lei.

$\S 2^{\circ}$. O Estado promoverá, sempre que possível, a solução consensual dos conflitos.

$\S 3^{\circ}$. A conciliação, a mediação e outros métodos de solução consensual de conflitos deverão ser estimulados por juízes, advogados, defensores públicos e membros do Ministério Público, inclusive no curso do processo judicial.

É simbólico que meios adequados de solução de conflitos constem no artigo $3^{\circ}$ da norma processual, dispositivo que repete o direito fundamental da inafastabilidade da jurisdição prevista no art. $5^{\circ}$, inciso XXXV, da Constituição Federal. Ainda, em que pese apenas se cite expressamente a arbitragem, a mediação e a conciliação, o legislador inseriu no dispositivo uma cláusula aberta que permite o emprego de outros meios de solução consensual de conflitos, desde que mais adequados ao caso.

A mediação e a conciliação são formas de autocomposição por excelência, em que há a participação de um terceiro facilitador que, em cada uma das técnicas, tem objetivos e atuação diversos. Na mediação, o mediador é responsável por criar um canal de comunicação entre as partes, ajudando a estabelecer um diálogo que permita às partes decidirem a melhor solução para o litígio, não podendo fazer propostas. Na conciliação, por sua vez, conciliador tem uma participação ativa na evolução das propostas de solução.

Segundo a doutrina, a conciliação "Diferencia-se da mediação, no sentido de buscar soluções imediatas para a contenda, ignorando a busca das causas geradoras do conflito;"29, e, por sua vez, "a mediação consiste num instituto que visa fundamentalmente dar fim efetivo ao conflito, emocional e jurídico", visando tratar as causas, "para que possam achar a solução mais favorável, sem se sentirem lesadas" ${ }^{30}$. No mesmo sentido, entende Fernanda Tartuce ${ }^{31}$

\footnotetext{
${ }^{28}$ BRASIL. Lei no 13.105 de 16 de março de 2015. Código de Processo Civil. In: Diário Oficial da República Federativa do Brasil, Brasília, DF. Disponível em: http://www.planalto.gov.br/ccivil_03/ato20152018/2015/lei/113105.htm Acesso em: 08 dez. 2019.

${ }^{29}$ CACHAPUZ, Rozane da Rosa. Mediação nos conflitos \& Direito de família. 1. ed. em 2003. $4^{\mathrm{a}}$ reimpr. Curitiba: Juruá, 2011.p. 18.

${ }^{30}$ CACHAPUZ, Rozane da Rosa. Mediação nos conflitos \& Direito de família. 1. ed. em 2003. $4^{\mathrm{a}}$ reimpr. Curitiba: Juruá, 2011. p. 29.

${ }^{31}$ TARTUCE, Fernanda. Processo civil no direito de família: teoria e prática. 3. ed. São Paulo: Método, 2018. p. 217.
} 
que há um objetivo de obter acordo por parte do conciliador, o que não existe para a figura do mediador: "O mediador não induz as pessoas a um acordo: ele contribui para o restabelecimento da comunicação de modo que os envolvidos gerem novas formas de relacionamento e equacionamento de controvérsias.".

Além das formas de solução consensuais nominadas, quais sejam, a conciliação e a mediação, que são técnicas de autocomposição por excelência, ainda podem ser citadas a negociação direta, os dispute boards, a transação por adesão, a negociação coletiva, e enfim, a que interessa ao presente trabalho: a solução de conflitos online, através de mecanismos digitais.

\subsection{Soluções de Conflitos em Formato Digital: Perspectivas Promissoras}

A busca pela solução de conflitos de forma digital vem ganhando visibilidade, e a solução de conflitos online passa a ser incluída como uma das portas existentes no sistema multiportas.

A Resolução n. 125/2010 do Conselho Nacional de Justiça é considerada um marco no tratamento e resolução de conflitos pelo Poder Judiciário, e inaugura a "Política Judiciária Nacional de tratamento adequado dos conflitos de interesses”. Essa nova política judiciária de solução de conflitos permitiu ao Judiciário reconhecer que pode - ou deve - abrir mão da imposição de uma solução heterocompositiva em todo e qualquer litígio, permitindo e estimulando que haja esferas de solução distintas.

Por conseguinte, conforme Charlise Paula Colet Gimenez e Fabiana Marion Spengler $^{32}$ explicam, instituir uma política pública nesse sentido é essencial para a construção de uma “cultura de paz", de alteridade e empoderamento das pessoas envolvidas, em que a pessoa pode tratar seu próprio litígio, o que contrapõe a ideia de supremacia da decisão do terceiro, a "cultura de sentença” visualizada por Kazuo Watanabe ${ }^{33}$, já trazida neste trabalho.

\footnotetext{
${ }^{32}$ GIMENEZ, Charlise Paula Colet. SPENGLER, Fabiana Marion. O mediador na resolução 125/2010 do CNJ: um estudo a partir do Tribunal Múltiplas Portas. 1. ed. Águas de São Pedro: Livronovo, 2016. p. 175.

33 WATANABE, Kazuo. Cultura da sentença e cultura da pacificação. In: YARSHELL, Flávio Luiz. MORAES, Maurício Zanoide de. (Org.) Estudos em homenagem à professora Ada Pellegrini Grinover. São Paulo: Editora DPJ, 2005. p. 689.
} 
O artigo $6^{\circ}$ da Resolução n. 125/2010 do CNJ, após a Emenda n. 2, editada em 2016, passou a prever que compete ao CNJ " $\mathrm{X}$ - criar Sistema de Mediação e Conciliação Digital ou a distância [...]"34, tanto em questões pré-processuais como em demandas em curso.

Não obstante a previsão na Resolução do CNJ, na Lei 13.140/2015 (Lei de Mediação), considerada o marco legal da mediação no Brasil, dispôs o art. 46 que "Art. 46. A mediação poderá ser feita pela internet ou por outro meio de comunicação que permita a transação à distância, desde que as partes estejam de acordo.” ${ }^{35}$, o que demonstra que o legislador também evoluiu sua atuação para compatibilizar a solução de conflitos com a era digital e a sociedade de informação.

\subsubsection{Noções Gerais sobre as ODR - Online Dispute Resolution}

A Online Dispute Resolution (ODR) é, conforme sua tradução, uma forma de resolução de conflitos online. Fernando Sérgio Tenório de Amorim ${ }^{36}$ esclarece que consiste em espécie do gênero ADR - Alternative Dispute Resolution, ou, conforme parte da doutrina já citada, espécie de resolução adequada ou complementar de conflitos.

Não significa, contudo, apenas modalidade nova, mas sim nova plataforma onde outros mecanismos e métodos podem ser empregados. É possível, portanto, que seja realizada um processo arbitral online, uma sessão de mediação online, uma audiência de instrução e julgamento com parte fisicamente distantes ${ }^{37}$. Enfim, a resolução de conflitos

\footnotetext{
${ }^{34}$ CONSELHO NACIONAL DE JUSTIÇA. Resolução n. 125/2010. Dispõe sobre a Política Judiciária Nacional de tratamento adequado dos conflitos de interesses no âmbito do Poder Judiciário e dá outras providências. Disponível em: http://www.cnj.jus.br/images/atos_normativos/resolucao/resolucao_125 29112010_11032016162839.pdf Acesso em: 30 nov. 2019.

${ }^{35}$ BRASIL. Lei $n^{\circ} 13.140$ de 26 de junho de 2015. Dispõe sobre a mediação entre particulares como meio de solução de controvérsias e sobre a autocomposição de conflitos no âmbito da administração pública; altera a Lei $n^{\circ} 9.469$, de 10 de julho de 1997 , e o Decreto $n^{\circ} 70.235$, de 6 de março de 1972; e revoga o $\S 2^{\circ}$ do art. $6^{\circ}$ da Lei n ${ }^{\circ}$ 9.469, de 10 de julho de 1997. In: Diário Oficial da República Federativa do Brasil, Brasília, DF. Disponível em: http://www.planalto.gov.br/ccivil_03/_ato2015-2018/2015/lei/113140.htm Acesso em: 09 dez. 2019.

36 AMORIM, Fernando Sérgio Tenório de. A resolução online de litígios (ODR) de baixa intensidade: perspectivas para a ordem jurídica brasileira. Pensar Revista de Ciências Jurídicas, Fortaleza, v. 22, n. 2, p. 514-539, maio/ago., 2017. Disponível em: 〈https://periodicos.unifor.br/rpen/article/view/5397> Acesso em: 02 dez. 2019. p. 515.

${ }^{37}$ Destaca-se que o cenário verificado desde março de 2020 deu azo à implantação de mais ferramentas virtuais em prol do acesso à justiça. Após a declaração de pandemia pela Organização Mundial da Saúde, em função da disseminação do novo corona vírus, e a identificação de casos no Brasil, o Poder Judiciário passou a implantar o home office e incentivar as audiências virtuais, sejam estas em $1^{\circ}$ grau de jurisdição, até na mais
} 
online é o emprego da tecnologia integrada aos meios de solução já existentes offline bem como permite o desenvolvimento de novos mecanismos. A mediação digital, por exemplo, é nominalmente citada na Resolução n. 125 do CNJ bem como na Lei de Mediação.

Fernando Sérgio Tenório de Amorim ${ }^{38}$ cita algumas experiências no mundo, como o CyberTribunal, projeto implantando por uma universidade canadense de 1996 a 1999, que promovia a mediação e arbitragem online, não se convertendo em jurisdição, mas sim em resolução por meio digital por voluntariedade das partes, que submetem voluntariamente controvérsias para solução.

Podem ser observados diversos benefícios de práticas como estas, já que a utilização de tecnologia permite colocar as partes em contato, ainda que distantes, e não exige o deslocamento a um mesmo espaço físico, e, como consequência, também promove economia de recursos financeiros ou humanos - não ocorre a instalação de infraestrutura predial como a dos CEJUSCs, bem como, em alguns casos, em que não há a intervenção de um terceiro mediador ou conciliador (negociação direta e canais de comunicação), não se faz necessário a manutenção de quadro de profissionais - o que para o Poder Judiciário é bastante significativo em termos de economia.

\subsubsection{Negociação Direta nas Relações de Consumo e Comércio Eletrônico}

Uma das ferramentas que caracteriza forma de ODR é a resolução de conflitos por meio de negociação direta, forma consensual de solução que não conta com a participação de um terceiro facilitador. Antônio do Passo Cabral e Leonardo Carneiro da Cunha ${ }^{39}$ definem a negociação direta como uma "resolução colaborativa de disputas (collaborative law)", sendo espécie de "mediação sem mediador".

alta Corte do país, o Supremo Tribunal Federal, que se reúne virtualmente para decidir sobre questões de interesse fundamental à ordem jurídica. As audiências virtuais, que incluem as audiências de conciliação e mediação, representam ferramenta tecnológica aliada à resolução de conflitos, evitando que o trâmite processual seja interrompido e garantindo a prestação jurisdicional e o acesso à justiça mesmo em tempos de pandemia.

38 AMORIM, Fernando Sérgio Tenório de. A resolução online de litígios (ODR) de baixa intensidade: perspectivas para a ordem jurídica brasileira. Pensar Revista de Ciências Jurídicas, Fortaleza, v. 22, n. 2, p. 514-539, maio/ago., 2017. Disponível em: <https://periodicos.unifor.br/rpen/article/view/5397> Acesso em: 02 dez. 2019. p. 519-520.

${ }^{39}$ CABRAL, Antonio do Passo. CUNHA, Leonardo Carneiro. Negociação direta ou resolução colaborativa de disputas (collaborative law): "mediação sem mediador". Revista de Processo, vol. 259, setembro de 2016. p. 471-489. São Paulo: RT, 2016. p. 471. 
Atualmente, o e-commerce (comércio eletrônico) coexiste com o comércio tradicional, e confere vantagens ao comerciante e consumidor, ainda que enfrente riscos diferenciados na exploração, como a segurança digital. Entre as vantagens, permite uma ampla comparação de preços, obtenção de produtos físicos a serem enviados ou mesmo produtos digitais para download, e muitas empresas possuem apenas o estabelecimento virtual, sem um ponto físico, o que é representa uma grande economia, enfim, são muitos fatores que levam a preferência pelo comércio eletrônico por muitos fornecedores e consumidores, tornando-o o presente e o futuro do comércio ${ }^{40}$.

As relações de consumo e os negócios celebrados em comércio eletrônico, sem dúvida, podem gerar conflitos entre as partes, pelos mesmos motivos que o convencional, como a constatação de defeitos ou vícios no produto, problemas na entrega, cobrança indevida etc. E, muitos sites de comércio eletrônico, cientes dessa realidade e dispostos a minorar as consequências negativas dos conflitos, como devoluções e avaliações negativas, passaram a prever em seu próprio sistema uma forma de solucionar reclamações relativas às compras.

A título de exemplo, podem ser citados os sites eBay e AliExpress, ambas plataformas que contém um sistema de lojas cadastradas e o comprador opta por alguma dessas lojas (que pode ser, inclusive, uma pessoa física vendendo produtos). Caso haja algum problema com a compra ou entrega, é possível abrir uma "disputa". Nesta disputa, o comprador manifesta sua reclamação em contato direto com o vendedor, sem intermediação do site, que apenas oferece a plataforma para que essa comunicação ocorra.

Trata-se de forma de negociação direta, para que as partes possam solucionar entre si os problemas por meio do site. Os envolvidos não se conhecem nem possuem relação prévia, correspondendo às vezes a pessoas de países diferentes, mas, sem dúvida, possuem interesses comuns em solucionar a questão com mais rapidez e eficiência. $\mathrm{O}$ vendedor preocupa-se em manter sua reputação no site, que o classifica conforme as avaliações dos clientes e do resultado da solução de disputas, e o comprador quer seu problema resolvido. Ao final, não ocorrendo consenso sobre a disputa, podem as partes abrir as outras portas do sistema multiportas.

\footnotetext{
${ }^{40}$ TEIXEIRA, Tarcisio. Comércio eletrônico: conforme o Marco Civil da Internet e a regulamentação do $e$ -
} commerce no Brasil. 1. ed. São Paulo: Saraiva, 2015. p. 28-31. 
Ressalta-se que, para Fernando Sérgio Tenório de Amorim ${ }^{41}$, o sistema de avaliação de vendedores não é considerado propriamente uma ODR:

A avaliação das partes não se constitui, a rigor, em medida executória da decisão proferida no âmbito de um procedimento de Resolução Online de Conflitos. Seu objetivo principal consiste em incentivar os contratantes a cumprir o contrato, sob pena de perda da sua credibilidade no mercado.

Desse modo, a resolução de disputas não se confunde com a avaliação das partes após a compra e venda ou após a solução em si, sendo etapa autônoma da relação de comércio eletrônico, mas que reflete no empenho pela busca de uma solução.

Superados tais sistemas internacionais de ODR, merece destaque a iniciativa brasileira a respeito de Direito do Consumidor, pela criação do portal "Consumidor.gov.br", que permite a comunicação através de uma conexão direta entre as empresas participantes e os consumidores que se cadastrem e entrem em contato. Ele é definido pelo próprio portal como "um serviço público e gratuito que permite a interlocução direta entre consumidores e empresas para solução alternativa de conflitos de consumo pela internet." 42

Justamente, nesse portal, os consumidores interessados enviam suas reclamações, dúvidas e solicitações direcionadas às empresas cadastradas, as quais devem analisar e responder dentro de um prazo de 10 dias a reclamação aberta. O consumidor então terá um prazo de 20 dias para comentar e avaliar sua satisfação com a resposta do fornecedor, e, caso não seja solucionado o problema, recomenda-se o atendimento dos órgãos de defesa do consumidor, bem como acesso ao próprio Poder Judiciário.

No portal é possível encontrar diversos dados que elucidam o índice de efetividade da resolução de demandas consumeristas ${ }^{43}$, em que o índice geral referente ao ano de 2017 foi de $80,6 \%$ de resolutividade dos casos. No total, houve 470.748 reclamações finalizadas, e as empresas de telecomunicações foram as mais reclamadas no portal $(43,3 \%)$, seguidas pelos bancos, financeiras e administradoras de cartão (20,4\%), depois pelos bancos de dados e cadastro de consumidores $(14,5 \%)$ e pelo comércio eletrônico $(8 \%)$.

\footnotetext{
${ }^{41}$ AMORIM, Fernando Sérgio Tenório de. A resolução online de litígios (ODR) de baixa intensidade: perspectivas para a ordem jurídica brasileira. Pensar Revista de Ciências Jurídicas, Fortaleza, v. 22, n. 2, p. 514-539, maio/ago., 2017. Disponível em: 〈https://periodicos.unifor.br/rpen/article/view/5397> Acesso em: 02 dez. 2019. p. 536.

${ }_{42}$ BRASIL. Consumidor.gov.br. Disponível em: https://www.consumidor.gov.br/pages/principal/?1583242233788 Acesso em: 10 dez. 2019.

43 BRASIL. Consumidor.gov.br. Infográficos. Disponível em: https://www.consumidor.gov.br/pages/indicador/geral/abrir Acesso em: 10 dez. 2019.
} 
Observa-se que o uso das plataformas digitais permite uma aproximação entre empresas quer sejam estas pequenas ou sejam consideradas de grande porte, cumprindo o objetivo primordial de viabilizar um contato direto para fins de solução de conflitos decorrentes da relação de consumo ou decorrentes de comércio eletrônico, prevenindo o agravamento do problema e evitando o acionamento de outras portas de resolução de conflitos. É, de fato, ferramenta essencial na sociedade de informação.

\subsubsection{Mediação e Conciliação Digital no Brasil}

A mediação e a conciliação digitais implicam na realização de sessões da mesma forma como ocorreriam presencialmente, mas através de plataformas digitais. As mesmas técnicas são empregadas, mas com as partes e mediadores ou conciliadores fisicamente distantes ${ }^{44}$.

Os mecanismos digitais permitem essa aproximação virtual para que as partes possam discutir o conflito que há entre elas, comunicação muitas vezes inviável sem tais meios. Observa-se que, "Longe de ser apenas mais uma ferramenta de comunicação, a Internet tornou-se o próprio espaço no qual se constituem inúmeras relações jurídicas, o que exige dos sistemas jurídicos nacionais uma nova abordagem sobre o velho problema da resolução de litígios." 45

Entre alguns exemplos de solução digital de conflitos pela mediação, conciliação e arbitragem, existe uma Startup cujos resultados a levaram a ser reconhecida pelo CNJ, recebendo o prêmio "Conciliar é Legal" ${ }^{46}$ na categoria Mediação e Conciliação Extrajudicial do ano de 2018. Chamada "Mediação Online", ou apenas "MOL”, a Startup já lidou com mais de 2.500 casos, gerando às empresas parceiras uma economia de cerca de $\mathrm{R} \$ 16,5$

\footnotetext{
${ }^{44}$ Especialmente com relação às audiências virtuais realizadas durante a suspensão de trabalho presencial durante a pandemia do novo corona vírus, o Conselho Nacional de Justiça editou normativas dentro da sua competência, especialmente a Resolução n. 313 de 19/03/2020 e a Resolução n. 314 de 07 de maio de 2020, que autorizam e criam alternativas para o andamento de processos e realização de atos processuais durante a suspensão do trabalho presencial.

${ }^{45}$ AMORIM, Fernando Sérgio Tenório de. A resolução online de litígios (ODR) de baixa intensidade: perspectivas para a ordem jurídica brasileira. Pensar Revista de Ciências Jurídicas, Fortaleza, v. 22, n. 2, p. 514-539, maio/ago., 2017. Disponível em: 〈https://periodicos.unifor.br/rpen/article/view/5397> Acesso em: 02 dez. 2019. p. 515.

${ }^{46}$ Sobre o trabalho desenvolvido pela Startup e seus resultados, ver: http://www.cnj.jus.br/noticias/cnj/88527startup-brasileira-de-mediacao-digital-vence-premio-conciliar-e-legal-2018
} 
milhões, através da realização de acordos com os reclamantes - entre as empresas que usufruem dos serviços prestados está o Banco Itaú.

Todas as sessões são online e os acordos firmados são submetidos à homologação judicial, sendo considerados título executivo extrajudicial, facilitando sua execução em face de um posterior descumprimento.

Por fim, uma importante iniciativa é aquela que concretiza o disposto no art. $6^{\circ}$, inciso X, da Resolução n. 125/2010 do CNJ, previamente comentado. O CNJ desenvolveu um sistema online de mediação digital, acessível pelo endereço http://www.cnj.jus.br/mediacaodigital/. Instalado em 2016, o sistema foi suspenso ao final do ano de 2018 para reformulações, permitindo apenas que os pedidos realizados até a referida suspensão continuassem.

O procedimento no sistema envolve empresas previamente cadastradas - ou seja, que voluntariamente se propuseram a participar da solução de disputas - e o reclamante, que expõe sua insatisfação. A reclamada possui 20 dias corridos para responder a solicitação, e poderá até mesmo entrar em contato com o reclamante diretamente por telefone ou mensagem no sistema. Ao final, o acordo poderá ser homologado por um magistrado ou por meio da plataforma digital, tornando-se também um título executivo extrajudicial, conferindo segurança e exequibilidade.

Os benefícios que a ODR traz para a solução de conflitos são vários, aliados aos benefícios comuns dos meios "alternativos", e, portanto, Fabiana Marion Spengler e Humberto Dalla Bernardina de Pinho colocam a mediação digital como uma política judiciária de acesso à justiça ${ }^{47}$, cada vez mais necessária como se observa diante da conjuntura atual.

A facilidade de comunicação, a possibilidade de dispensa de contratação de advogado em certos casos (muito embora seja algo recomendado), a celeridade, a autonomia das partes ao lidar com seus próprios conflitos, tornam a solução online uma porta no sistema de resolução de conflitos, alocando-se bem na sociedade de informação que caminha para um amplo acesso à tecnologia e empoderamento das partes.

\footnotetext{
${ }^{47}$ SPENGLER, Fabiana Marion; PINHO, Humberto Dalla Bernardina de. A mediação digital de conflitos como política judiciária de acesso à justiça no Brasil. Revista da Faculdade de Direito UFMG. Belo Horizonte, n. 72, pp. 219-257, jan./jun. 2018.20 Disponível https://www.direito.ufmg.br/revista/index.php/revista/article/viewFile/1923/1817 Acesso em: 29 nov. 2019. p. 219.
} 


\section{CONCLUSÃO}

No presente trabalho, destacou-se a fluidez da realidade, sujeita a constantes mudanças econômicas, sociais, culturais, e especialmente, mudanças tecnológicas. Após a universalização do acesso à internet, permitindo que qualquer pessoa no mundo pudesse, dentro das possibilidades fáticas, utilizar a rede, os usuários usufruem da oportunidade de transmissão de mensagens, imagens, vídeos, produção de conteúdo jornalístico, organização de movimentos sociais, enfim, informar, se informar e ser informado - e tudo isso se converte em informação, tudo que se converte em códigos transmissíveis. Por tais motivos, vivemos em uma "sociedade de informação".

Em que pese há uma visão de "democratização da internet”, não são todas as pessoas que possuem acesso a essa ferramenta, seja em razão dos seus custos ou mesmo da ausência de conhecimento sobre o uso e manutenção. Foram trazidos no estudo dados recentes sobre a inclusão digital (e, consequentemente, sobre a exclusão digital), demonstrando que há um crescimento importante nos últimos anos, mas ainda há 39\% dos domicílios no Brasil sem acesso à internet.

Sem acesso à internet, não há, como consequência, acesso à toda a amplitude de informações, nem acesso a alguns serviços públicos, ações do "governo eletrônico", que buscam facilitar a vida de pessoas que usufruem da tecnologia para emissão de certidões, agendamento de atendimentos, controle das finanças e da moralidade administrativa etc. Em face dos dados acerca da exclusão digital, espera-se as políticas públicas sejam direcionadas a permitir que o maior número de pessoas possa se beneficiar do uso da internet.

Neste ponto, foi dada atenção ao Poder Judiciário e sua relação com a tecnologia, adaptando-se à irreversível tendência de informatização, sem deixar de cumprir com seu objetivo primordial: a realização do acesso à justiça.

Verificou-se que o acesso à justiça, enquanto acesso aos meios e acesso também a um resultado justo, em sua dupla acepção, é otimizado por iniciativas como a informatização processual, a regulamentação do processo eletrônico e a prática de atos processuais eletrônicos por meio da Lei $\mathrm{n}^{\circ}$ 11.419/2006. A estatística se mostrou aliada na compreensão da dimensão do processo informatizado, notadamente pelo relatório "Justiça em Números", 
do Conselho Nacional de Justiça, em que se observou um positivo crescimento no número total de processos eletrônicos.

Todavia, ainda que seja útil para a prestação jurisdicional, a informatização dos processos não pode ser considerada a única forma legítima e eficaz de solucionar os conflitos que insurgem das relações sociais. Necessário o reconhecimento de outros meios que sejam adequados às peculiaridades de cada caso, o que corresponde a uma proposta de décadas, que estimulam formas "alternativas" à solução judicial, melhorando ainda mais o acesso à justiça.

Com efeito, os "meios alternativos de solução de conflitos", os quais já são denominados também de meios "adequados" ou meios "complementares", adquiriram, com o tempo, um status de equivalência à via judicial, não mais como meios secundários. Podem ser citados a conciliação, a mediação, a arbitragem (aliás, expressamente nomeados no Código de Processo Civil em seu art. $3^{\circ}$ ), além de outros meios, como a negociação direta e as formas digitais de solução de conflito - o objetivo deste trabalho.

A solução online de conflitos é referida no corpo da Resolução n. 125/2010 do CNJ, bem como na Lei 13.140/2015 (Lei de Mediação). Há uma adaptação dos meios acima citados para as plataformas digitais, que permitem a aproximação de pessoas geograficamente distantes, mas que no ciberespaço podem se encontrar. Tais meios, quando transportados para a forma digital, denominam-se Online Dispute Resolution (ODR).

Os meios de solução digitais possuem uma grande amplitude, alcance global, bem como permitem o tratamento de conflitos entre pessoas físicas e jurídicas, acerca de conflitos consumeristas, civis, trabalhistas, familiares, e também de conflitos oriundos da própria utilização da internet, como no comércio eletrônico.

O acesso a esses meios confere facilidade de comunicação, celeridade, permite o desenvolvimento da autonomia das partes ao lidar com seus próprios conflitos e garantem que, em situações em que seja impossível ou dificultoso a busca pela solução offline de forma presencial, exista a solução online, configurando mais uma porta no sistema multiportas de resolução de conflitos. A sociedade de informação caminha para um amplo acesso à tecnologia, com a resolução de conflitos não mais dependendo apenas de um meio, mas sim de uma pluralidade de meios, os quais se adaptam à inovação do modo de vida atual. 
Desse modo, a importância das formas digitais de solução de conflito, as ODR, é inegável dentro do contexto da sociedade de informação, mostrando-se cada vez mais relevante também na própria política judiciária nacional de acesso à justiça e de tratamento de conflitos, concretizando as faces do acesso à justiça, seja por meio da prestação jurisdicional ou por outros meios.

\section{REFERÊNCIAS}

ALMEIDA, Rafael Alves de. ALMEIDA, Tania. CRESPO, Mariana Hernandez. Tribunal multiportas: investindo no capital social para maximizar o sistema de solução de conflitos no Brasil. Rio de Janeiro: Editora FGV, 2012.

AMORIM, Fernando Sérgio Tenório de. A resolução online de litígios (ODR) de baixa intensidade: perspectivas para a ordem jurídica brasileira. Pensar Revista de Ciências Jurídicas, Fortaleza, v. 22, n. 2, p. 514-539, maio/ago., 2017. Disponível em: 〈https://periodicos.unifor.br/rpen/article/view/5397> Acesso em: 02 dez. 2019.

BAUMAN, Zygmunt. Modernidade líquida. Tradução Plínio Dentzien. Rio de Janeiro: Jorge Zahar Ed., 2001.

BRASIL. Lei $n^{\circ} 13.105$ de 16 de março de 2015. Código de Processo Civil. In: Diário Oficial da República Federativa do Brasil, Brasília, DF. Disponível em: http://www.planalto.gov.br/ccivil_03/_ato2015-2018/2015/lei/113105.htm Acesso em: 08 dez. 2019.

BRASIL. Lei n ${ }^{\circ} 13.140$ de 26 de junho de 2015. Dispõe sobre a mediação entre particulares como meio de solução de controvérsias e sobre a autocomposição de conflitos no âmbito da administração pública; altera a Lei no 9.469, de 10 de julho de 1997, e o Decreto $\mathrm{n}^{\circ} 70.235$, de 6 de março de 1972; e revoga o $\S 2^{\circ}$ do art. $6^{\circ}$ da Lei $n^{\circ} 9.469$, de 10 de julho de 1997. In: Diário Oficial da República Federativa do Brasil, Brasília, DF. Disponível em: http://www.planalto.gov.br/ccivil_03/_ato20152018/2015/lei/113140.htm Acesso em: 09 dez. 2019.

CABRAL, Antonio do Passo. CUNHA, Leonardo Carneiro. Negociação direta ou resolução colaborativa de disputas (collaborative law): "mediação sem 
mediador”. Revista de Processo, vol. 259, setembro de 2016. São Paulo: RT, 2016, p. 471-489.

CACHAPUZ, Rozane da Rosa. Mediação nos conflitos \& Direito de família. 1. ed. em 2003. $4^{\mathrm{a}}$ reimpr. Curitiba: Juruá, 2011.

CAPPELLETTI, Mauro; GARTH, Bryant. Acesso à justiça. 1 ed. Porto Alegre: Sergio Fabris, 1988.

CASTELLS, Manuel. A sociedade em rede. A era da informação: economia, sociedade e cultura. v. 1. Tradução Roneide Venancio Majer. 6. ed. 2002.

CINTRA, Antonio Carlos Araújo; GRINOVER. Ada Pellegrini; DINAMARCO, Cândido Rangel. Teoria geral do processo. 26. ed. São Paulo: Malheiros, 2010.

COMITÊ GESTOR DA INTERNET (CGI). Pesquisa sobre o uso das tecnologias de informação e comunicação nos domicílios brasileiros: TIC domicílios (2017). Núcleo de Informação e Coordenação do Ponto BR - São Paulo: Comitê Gestor da Internet no $\quad$ Brasil, $2018 . \quad$ Disponível em: <https://www.cetic.br/pesquisa/domicilios/publicacoes > Acesso em: 02 dez. 2019.

CONSELHO NACIONAL DE JUSTIÇA (CNJ). Justiça em Números 2019: (ano base 2018). Brasília: Conselho Nacional de Justiça, 2019. Disponível em: <https://www.cnj.jus.br/files/conteudo/arquivo/2019/08/4668014df24cf825e718738 3564e71a3.pdf> Acesso em: 30 nov. 2019.

CONSELHO NACIONAL DE JUSTIÇA. Resolução n. 313/2020. Estabelece, no âmbito do Poder Judiciário, regime de Plantão Extraordinário, para uniformizar o funcionamento dos serviços judiciários, com o objetivo de prevenir o contágio pelo novo Coronavírus - Covid-19, e garantir o acesso à justiça neste período emergencial. Disponível em: 〈https://atos.cnj.jus.br/atos/detalhar/3249> Acesso em: 22 mai. 2020.

CONSELHO NACIONAL DE JUSTIÇA. Resolução n. 314/2020. Prorroga, no âmbito do Poder Judiciário, em parte, o regime instituído pela Resolução nº 313, de 19 de março de 2020, modifica as regras de suspensão de prazos processuais e dá outras providências. Disponível em: 〈https://atos.cnj.jus.br/atos/detalhar/3283> Acesso em: 22 mai. 2020. 
CONSELHO NACIONAL DE JUSTIÇA. Resolução n. 125/2010. Dispõe sobre a Política

Judiciária Nacional de tratamento adequado dos conflitos de interesses no âmbito do Poder Judiciário e dá outras providências. Disponível em: <http://www.cnj.jus.br/images/atos_normativos/resolucao/resolucao_125_2911201 0_11032016162839.pdf> Acesso em: 30 nov. 2019.

CUNHA, Leonardo Carneiro. Art. $1^{\text {o }}$ da Lei 13.140/2015. p. 1-7. In: CABRAL, Trícia Navarro Xavier. CURY, César Felipe. (Orgs.). Lei de mediação comentada artigo por artigo: dedicado à memória da Prof ${ }^{\mathrm{a}}$. Ada Pellegrini Grinover. 1. ed. Indaiatuba, SP: Editora Foco, 2018.

EUGENIO, Alexia Domene; LIGERO, Gilberto Notário. A internet como veículo

libertário: a incorporação da rede na vida social. In: Anais do III Simpósio

Internacional de Análise Crítica do Direito - Jacarezinho (PR): Universidade Estadual do Norte do Paraná, 2013. p. 2176-2190. Disponível em: http://siacrid.com.br/repositorio/2013/anais-do-iii-simposio-de-analise-critica-dodireito.pdf Acesso em: 10 dez. 2019.

GIMENEZ, Charlise Paula Colet. SPENGLER, Fabiana Marion. O mediador na resolução 125/2010 do CNJ: um estudo a partir do Tribunal Múltiplas Portas. 1. ed. Águas de São Pedro: Livronovo, 2016.

LEMOS, André; LÉVY, Pierre. O futuro da internet: em direção a uma ciberdemocracia. São Paulo: Paulus, 2010.

MANCUSO, Rodolfo de Camargo. Acesso à justiça: condicionantes legítimas e ilegítimas. Salvador: JusPodivm, 2018.

SPENGLER, Fabiana Marion; PINHO, Humberto Dalla Bernardina de. A mediação digital de conflitos como política judiciária de acesso à justiça no Brasil. Revista da Faculdade de Direito UFMG, Belo Horizonte, n. 72, pp. 219-257, jan./jun. 2018. Disponível em: 〈https://www.direito.ufmg.br/revista/index.php/revista/article/viewFile/1923/1817> Acesso em: 29 nov. 2019.

TARTUCE, Fernanda. Processo civil no direito de família: teoria e prática. 3. ed. São Paulo: Método, 2018. 
Rio de Janeiro. Ano 15. Volume 22. Número 3. Setembro a Dezembro de 2021

Periódico Quadrimestral da Pós-Graduação Stricto Sensu em Direito Processual da UERJ

Patrono: José Carlos Barbosa Moreira (in mem.). ISSN 1982-7636. pp. 981-1005 www.redp.uerj.br

TEIXEIRA, Tarcisio. Comércio eletrônico: conforme o Marco Civil da Internet e a regulamentação do e-commerce no Brasil. 1. ed. São Paulo: Saraiva, 2015.

THEODORO JÚNIOR, Humberto. Curso de direito processual civil - teoria geral do direito processual civil, processo de conhecimento e procedimento comum. vol. 1. 56. ed. Rio de Janeiro: Forense, 2015.

WATANABE, Kazuo. Cultura da sentença e cultura da pacificação. In: YARSHELL, Flávio Luiz. MORAES, Maurício Zanoide de. (Org.) Estudos em homenagem à professora Ada Pellegrini Grinover. São Paulo: Editora DPJ, 2005. 